\title{
RANCANG BANGUN PENGEMBANGAN APLIKASI PEMILIHAN PRESIDEN MAHASISWA MELALUI SMS GATEWAY
}

\author{
M. Hasim Siregar \\ Prodi Teknik Informatika, Universitas Islam Kuantan Singingi \\ J1. Gatot Subroto KM 7, Kebun Nenas, Teluk Kuantan, Sungai Jering, Kuantan Singingi, \\ Kabupaten Kuantan Singingi, Riau 29566 \\ email: hasyimsiregar92@gmail.com
}

\begin{abstract}
Abstrak
Dalam era perkembangan Industri 4.o kita diharapkan mampu menerapkan proses-proses yang menggunakan teknologi digital dan transparansi, dalam era ini yang disebut era kaum milenial, sistem informasi bukan lagi sebuah kebutuhan pelengkap tapi kebutuhan yang utama yang hampir digunakan setiap hari dan setiap saat, kita selalu menggunakan handphone dimanapun kita berada. Penggunaan layanan SMS pada Handphone memudahkan kita sebagai penggunanya untuk memberi dan bertukar informasi secara realtime kapanpun, dimanapun dan tepat sasaran bagi penggunanya. Dalam perkembangan teknologi sms munculah suatu inovasi yang di namakan SMS Gateway yang kini banyak digunakan untuk promosi, memberikan informasi secara masal bahkan melakukan polling atau votting berupa pesan singkat melalui handphone. Dengan adanya teknologi SMS Gateway kita dapat memanfaatkannya dalam melakukan proses pemilihan Presiden Mahasiswa. Rancang Bangun Pengembangan Aplikasi Pemilihan Presiden Mahasiswa Melalui SMS Gatway ini adalah untuk memudahkan Mahasiswa dalam memilih Presiden Mahasiswa atau Badan Eksekutif Mahasiswa (BEM) untuk menggunakan Hak suaranya sehingga peran partisipasi aktif mahasiswa semakin meningkat, mengingat tempat pemungutan suara dapat dilakukan dimana saja tanpa mahasiswa hadir dikampus dalam melaksanakan Pemungutan Suara serta memudahkan dan menghemat biaya dan waktu dalam pengelolaan data pemungutan suara pemilihan presiden mahasiswa sehingga lebih efektif dan efisien.
\end{abstract}

Kata Kunci : SMS Gatway, SMS, e-votting, Presma, BEM

\section{PENDAHULUAN}

Di Era serba digital, informasi merupakan suatu yang mutlak yang mudah didapatkan dimana kita membutuhkan informasi yang kita butuhkan dapat kita peroleh secara insentifitas dan efektivitas secara online. Dalam era perkembangan Industri 4.o kita diharapkan mampu menerapkan proses-proses yang menggunakan teknologi digital dan transparansi, dalam era ini yang disebut era kaum milenial, system informasi bukan lagi sebuah kebutuhan pelengkap tapi kebutuhan yang utama yang hampir digunakan setiap hari dan setiap saat, kita selalu menggunakan handphone dimanapun kita berada. Penggunaan layanan SMS pada Handphone memudahkan kita sebagai penggunanya untuk memberi dan bertukar informasi secara realtime kapanpu, dimanapun dan tepat sasaran bagi penggunanya. Dalam perkembangannya teknologi sms munculah suatu inovasi yang dinamakan SMS Gateway yang kini banyak digunakan untuk promosi, memberikan informasi secara masal bahkan melakukan polling atau votting berupa teks dari perangkat seluler. Dengan adanya teknologi SMS Gateway kita dapat memanfaatkannya dalam melakukan proses pemilihan Presiden Mahasiswa. Rancang Bangun Pengembangan Aplikasi Pemilihan Presiden Mahasiswa Melalui SMS Gatway ini adalah untuk memudahkan Mahasiswa dalam memilih Presiden Mahasiswa atau Badan Eksekutif Mahasiswa (BEM) untuk menggunakan Hak suaranya sehingga peran partisipasi aktif mahasiswa semakin meningkat, mengingat tempat pemungutan suara dapat dilakukan dimana saja tanpa mahasiswa hadir dikampus dalam melaksanakan Pemungutan Suara serta 
Hal : $102-111$

memudahkan dan menghemat biaya dan waktu dalam pengelolaan data pemungutan suara pemilihan presiden mahasiswa sehingga lebih efektif dan efisien, dilihat dari keadaan lingkungan pada mahasiswa tidak seluruhnya memiliki perangkat selular smartphone yang bisa menggunakan internet maka dari itu penulis menggunakan e-votting dengan teknologi SMS Gateway. Perkembangan teknologi informasi yang semakin pesat telah mempengaruhi transformasi berbagai aspek kehidupan masyarakat dunia secara umum dan Indonesia khususnya. Aspek-aspek tersebut antara lain: ekonomi, politik, kesehatan, sosial maupun pendidikan. Perkembangan tersebut ditandai dengan kecepatan akses informasi yang cepat di berbagai kegiatan. Hal ini berakibat masyarakat lebih banyak bergantung pada perangkat teknologi informasi untuk mencapai berbagai tujuannya dan berbagai bentuk perangkat teknologi informasi diciptakan, baik perangkat keras maupun perangkat lunaknya guna memenuhi kebutuhan akan kecepatan dan keakuratan untuk mendapatkan informasi secara efektif dan efisien, salah satunya adalah teknologi internet[4]. Penulis dengan memperhatikan aspek-aspek penting diatas, bagaimana tingkat pemilih untuk presiden mahasiswa bisa dilakukan secara efektif baik dari panitia maupun mahasiswa sebagai pemilih dengan menggambarkan faktor-faktor keadaan terkait pengelolaan pemungutan suara presiden mahasiswa.

Berdasarkan dari permasalahan yang di analisis, maka penelitian yang dilaksanakan ini bertujuan :

a. Menghasilkan Sistem Pemilihan Presiden Mahasiswa yang Efektif, efisien dan tepat waktu.

b. Membantu panitia pemilihan Presiden Mahasiswa lebih hemat dalam segi anggaran.

Peneliti juga berharap agar mendapatkan manfaat penelitian ini sebagai:

a. Aplikasi Sistem Pemilihan yang Berdasarkan kebutuhan informasi yang Transparansi, cepat dan efisiensi

b. Adanya layanan informasi pemungutan suara dan e-votting bagi pemilih melalui SMS Gateway

c. Dapat digunakan langsung oleh semua pemilih di kampus untuk menggunakan hak [pilihnya dimanapun berada.

\section{TINJAUAN PUSTAKA}

\subsection{Definisi SMS Gateway}

SMS Gateway didefinisikan sebagai sebuah perangkat lunak tambahan yang digunakan untuk mempermudah pengiriman dan penerimaan teks atau binary short message melalui jaringan telepon selular digital dari sebuah komputer atau pada sebuah jaringan. SMS Gateway tidak hanya dapat mengirimkan pesan saja tetapi juga dapat dipergunakan untuk berbagai kepentingan lainnya, seperti melakukan perhitungan polling, melakukan transaksi perbankan, bahkan melacak keberadaan seseorang [8].

Penelitian sebelumnya yang berjudul "Pengembangan Aplikasi SMS Gateway Untuk Informasi Pendaftaran Peserta Didik Baru Di Sman 1 Jepara " telah menghasilkan sebuah layanan sms gateway untuk memudahkan para orangtua mendapatkan informasi mengenai penerimaan peserta didik baru serta dapat dimanfaatkan sekolah untuk menyebarkan informasi[1].

Penelitian lainnya dengan judul "Rancang Bangun Aplikasi Sistem Pemilihan Kepala Desa Yang Terintegrasi Dengan SMS Gateway “ menghasilkan aplikasi sistem informasi Pemilihan kepala desa dalam pengelolaan data dan membuat sms votting yang memfasilitasi daftar pemilih tetap yang tidak bisa hadir langsung ke tempat pemungutan suara untuk dapat menggunakan hak pilihnya[3]. 
Hal : $102-111$

Penelitian dengan judul "Prototipe sistem Informasi Geografis Fasilitas Kesetan di kota Cirebon berbasis Web " telah menghasilkan aplikasi sistem informasi fasilitas kesehatan dan menampilkan peta digital dan dapat di integrasikan melalui web.[4]

\subsection{Pengertian Gammu}

Gammu merupakan salah satu aplikasi yang dapat digunakan untuk mengontrol komunikasi (telepon).

Utilisasi dari perintah Gammu menyediakan akses ke berbagai fitur telepon selular. Namun, tingkat dukungan dari ponsel ke ponsel akan berbeda. Umumnya, fitur yang didukung adalah sebagai berikut [8]:

a. Daftar panggilan, inisiasi dan penanganan

b. Pengambilan, backup dan pengiriman SMS

c. Pengambilan SMS

d.Daftar buku telepon (export-import, dengan format standart seperti vCard)

e. Kalendar dan daftar tugas (export-import, dengan format standart seperti vCalendar atau iCalendar)

f. Pengambilan informasi telepon dan jaringan informasi

g. Akses ke file system telepon.

\subsection{Definisi E-voting}

Electronic voting adalah suatu metode

Pemungutan suara dan penghitungan suara dalam suatu pemilihan dengan menggunakan perangkat elektronik. Tujuan dari electronic voting adalah menyelenggarakan pemungutan suara dengan biaya hemat dan penghitungan suara yang cepat dengan menggunakan sistem yang aman dan mudah untuk dilakukan audit. Adanya e-voting Perhitungan suara akan lebih akurat dan cepat, bisa menghemat biaya pencetakan surat suara, melakukan pemungutan suara lebih sederhana, dan peralatan dapat digunakan berulang kali. E-voting adalah pengambilan suara dengan menggunakan media elektronik atau perangkat elektronik, the council of Europe (CoE), mendefinisikan sebagai sebuah perangkat pemberian suara secara elektronik sehingga memiliki kemampuan untuk mempercepat tabulasi data, menekan biaya pemilihan dan memiliki kontribusi untuk mencegah pemilih yang tidak berhak. "legal, Operational and technical standards for e-voting" dikemukakan oleh the committee of ministers of the council of the Europe tentang procedural safeguards menyatakan bahwa prosedur standar yang harus dimiliki e-voting adalah:

1. Transparency

2. Verifiability and accountability

3. Reliability and transparency [10]

Menurut Zafar dan Pilkjaer, menegaskan tentang adanya sejumlah aspek manfaat dari penerapan e-voting yaitu:

- Biaya: terkait sumber daya dan investasi yang lebih hemat dibanding dengan sistem tradisional yang ribet, kompleks dan tidak efisien.

- Waktu: terkait waktu pelaksanaan pemilihan yang lebih cepat dan kalkulasi hasil yang lebih tepat dibandingkan sistem yang tradisional.

- Hasil: terkait dengan kalkukasi hasil yang lebih tepat dan akurat serta minimalisasi terjadinya kasus human error selama sistem yang dibangun terjamin dari berbagai ancaman kejahatan.

- Transparansi: terkait dengan transparansi dari semua proses karena semua dilakukan oleh suatu sistem yang otomatis dan real time online. 
Hal : $102-111$

Sangat penting dalam menggunakan e-voting termasuk apakah ada ancaman terkait kerahasiaan dan keamanan kemudian apakah adopsi e-voting ini dapat menaikan ketertarikan pemilih dalam menggunakan hak pilihnya.

\section{a) Basis Data}

Basis data merupakan suatu sekumpulan data yang saling berelasi. Data sendiri merupakan fakta mengenai obyek, orang, dan lain - lain. Data dinyatakan dengan nilai (angka, deretan karakter, atau simbol). Basis data dapat mempercepat upaya pelayanan kepada pelanggan, sehingga dapat menghasilkan informasi dengan cepat dan tepat sehingga membantu pengambil keputusan untuk segera memutuskan suatu masalah berdasarkan informasi yang telah diketahui [8].

b) Organisasi Mahasiswa

Organisasi mahasiswa di Indonesia adalah organisasi yang bergerak dan beranggotakan mahasiswa di kampus. Secara umum, organisasi kampus dapat dikategorikan ke dalam 2 jenis, yaitu organisasi mahasiswainternal kampus dan eksternal kampus. Organisasi Mahasiswa Internal Kampus adalah Organisasi mahasiswa yang melekat pada pribadi kampus atau universitas, dan memiliki kedudukan resmi di lingkungan perguruan tinggi. Bentuknya dapat berupa Badan Legislatif Mahasiswa, Badan Eksekutif Mahasiswa, Senat Mahasiswa, Himpunan Mahasiwa Jurusan, dan Para Ketua Tingkat A. Organisasi Internal kampus pada suatu perguruan tinggi dapat bergabung dalam skala daerah, nasional dan bahkan internasional. Gabungan organisasi internal kampus beberapa perguruan tinggi ini disebut Organisasi Antar Kampus.

Badan perwakilan mahasiswa (BPM) adalah organisasi mahasiswa yang dibentuk pada saat pemberlakuan kebijakan NKK/BKK pada tahun 1978. Sejak 1978-1989, badan perwakilan mahasiswa hanya ada di tingkat fakultas bersama-sama dengan senat mahasiswa. Ada kerancuan istilah BPM dengan senat mahasiswa karena sama-sama berarti wakil. Hanya saja menurut aturan main, BPM dianggap berfungsi sebagai badan legislatif sedangkan senat mahasiswa menjalani fungsi eksekutif.

Badan eksekutif mahasiswa (BEM) ialah lembaga kemahasiswaan yang menjalankan organisasi serupa pemerintahan (lembaga eksekutif). Dipimpin oleh ketua/presiden BEM yang dipilih melalui pemilu mahasiswa setiap tahunnya. Di beberapa kampus masih digunakan nama senat mahasiswa (SM).

c) SDLC Waterfall

SDLC (System Development Life Cycle) Waterfall adalah daur hidup pengembangan sistem perangkat lunak dimana tahapannya dilakukan secara berurutan, kemajuan akan dianggap sebagai aliran yang semakin kebawah melalui tahapan yang harus dijalankan untuk membangun sebuah perangkat lunak komputer. Gambar 1 berikut adalah gambaran tahapan SDLC Waterfall.

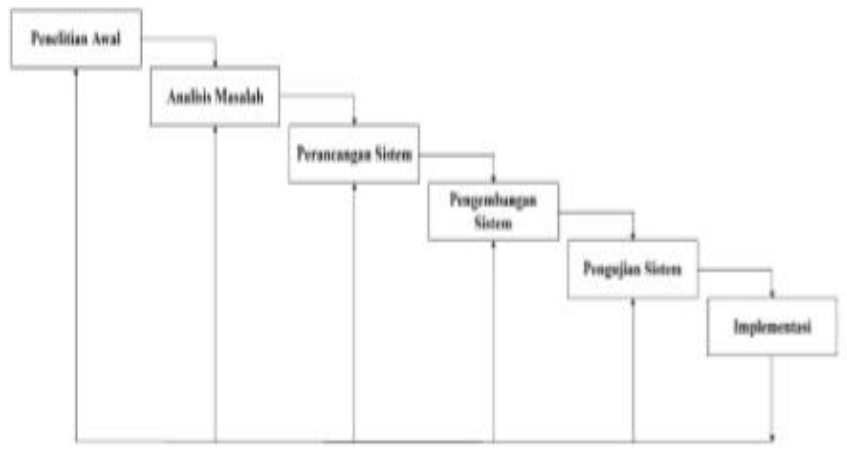

Gambar 1. Tahapan SDLC Waterfall [7] 
Hal : $102-111$

\section{METODOLOGI PENELITIAN}

Penelitian ini diawali dengan menganalisa kebutuhan sistem, mempertimbangkan setiap kriteria yang akan digunakan dalam perancangan sistem adapun menggunakan metode RUP (Rational Unfied Proses). RUP menggunakan konsep object oriented, dengan aktifitas yang berfokus pada pengembangan model dengan menggunakan tools Unified Model Language (UML), dengan tahapan meliputi Inception, Elaboration, Construction, dan Transition. Sedangkan teknik pengumpulan data yang peneliti gunakan, yaitu :.

Pada proses ini dilakukan beberapa tahapan sebagai berikut:

1. Studi Kelayakan

Mempelajari dan menganalisa proses-proses, dan identifikasi kondisi serta data-data yang dibutuhkan dalam rancangan aplikasi sehingga dapat memenuhi kebutuhan pelaksanaan pemilihan presiden mahasiswa dalam hal ini panitia untuk meningkatkan transparansi, efisiensi, dan keputusan. Pada proses ini dilakukan:

a. Wawancara dan kuesioner pada pihak terkait (panitia) dan pengguna (hak pilih)

b. Observasi

c. Mempelajari literatur dan buku yang terkait.

Perancangan sistem ini akan berfokus pada Pemilihan Presiden Mahasiswa. Proses Pemungutan masih belum memiliki sistem yang memadai, masih manual dalam pengelolaanya. Dengan mengetahui keadaan inilah yang melandasi pembuatan sistem yang dapat mengelola proses pengolahan data dan informasi untuk penggunaan Aplikasi Pemilihan Presiden Mahasiswa. Proses pengolahan data dan informasi dikelola oleh Panitia Pemilihan Presma sehingga data berpusat di Gedung Mahasiswa tersebut

2. Desain analisis dan fungsi

Melakukan desain system secara terstruktur, pada perancangan sistem ini menggunakan metode RUP konsep object oriented, berfokus pada model menggunakan UML. Kemudian dilanjutkan pada Context Diagram, desain file, desain tabel, relasi table dan sebagainya sehingga membentuk system lengkap sesuai dengan fungsi-fungsi aplikasi yang dikehendaki.

\section{c. Review Literatur dan Buku}

Dari Ketiga proses diatas dilakukan proses pengecekan untuk mengecek perubahan. Dalam melakukan pengecekan terhadap hasil wawancara dibuatkan sebuah laporan berupa dokumentasi. Setelah melakukan tahapan pengumpulan data, maka dilanjutkan ke aktivitas selanjutnya yaitu pendefinisian aplikasi yang akan dibuat. Beberapa hal yang perlu digambarkan terkait aplikasi yang akan dibuat adalah sebagai berikut

1. Aplikasi yang akan dibuat adalah aplikasi layanan informasi pemilihan presiden Mahasiswa dengan e-votting menggunakan sms gateway adapun aplikasi yang akan dibuat nantinya akan digunakan untuk menangani setiap kegiatan Pemungutan Suara seperti pendaftaran pemilih tetap, informasi pemilihan presma, kampanye dan pemungutan suara.

2. Aplikasi ini hanya digunakan untuk satu sisi, yaitu sisi petugas. Mahasiswa atau calon pemilih tidak akan bersentuhan secara langsung terhadap aplikasi hanya melaui sms pada handphone miliknya

\section{HASIL DAN PEMBAHASAN}

Hasil penelitian ini adalah membuat aplikasi Sistem Pemilihan Presiden mahasiswa melalui SMS Gateway bertujuan memberikan kemudahan dan meningkatkan partisipasi mahasiswa dalam pemilihan Presiden mahasiswa di kampusnya, serta memfasilitasi para pemilih untuk menggunakan hak suaranya dan memudahkan panitia pemilihan dalam 
Hal : $102-111$

pengelolaannya, fitur ini meliputi pendaftaran data daftar pemilih tetap, pengolahan data daftar hadir pemilih tetap, pengolahan data

perhitungan suara, membuat surat undangan melalui sms massal, melakukan kampanye untuk calon Presma, melaksanakan pemilihan Presma secara e-votting dan membuat laporan hasil pemilihan Presiden Mahasiswa

a. Desain Sistem

1) Usecase Diagram

Melalui Pemodelan Kasus Penggunaan (Usecase Modeling), kebutuhan dasar actor diidentifikasi dan bagaimana kebutuhan tersebut akan dipenuhi oleh system. Hubungan interaksi antara actor dan sistem ini yang disebut Usecase [6]

2) Diagram Kelas

Diagram kelas Menggambarkan struktur sistem dari segi pendefinisian kelas-kelas yang akan dibuat untuk membangun sistem [5]. Diagram kelas dibuat agar programmer membuat kelas-kelas sesuai dengan rancangan di dalam diagram antara dokumentasi perancangan dan perangkat lunak sinkron.

\section{3) Spesifikasi Basis Data}

Dalam penelitian ini basis data dirancang untuk menyimpan data antaralain: Daftar pemilih tetap, SmsVotting, Calon Presma, Perhitungan suara dan admin.

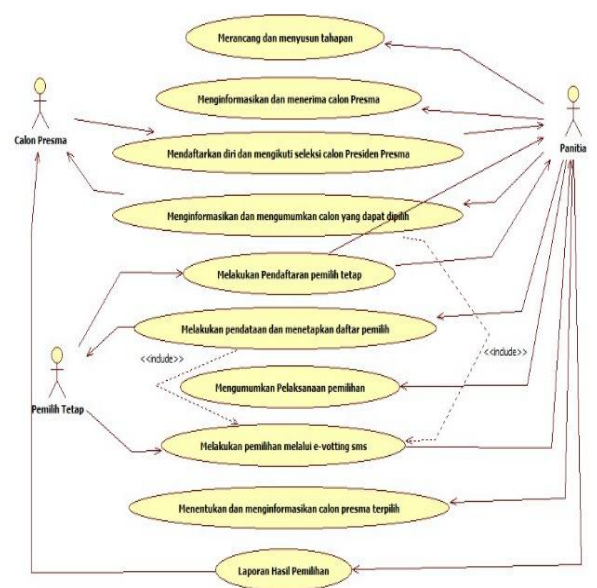

Gambar 2. UseCase Diagram Pemilihan Presma yang akan berjalan

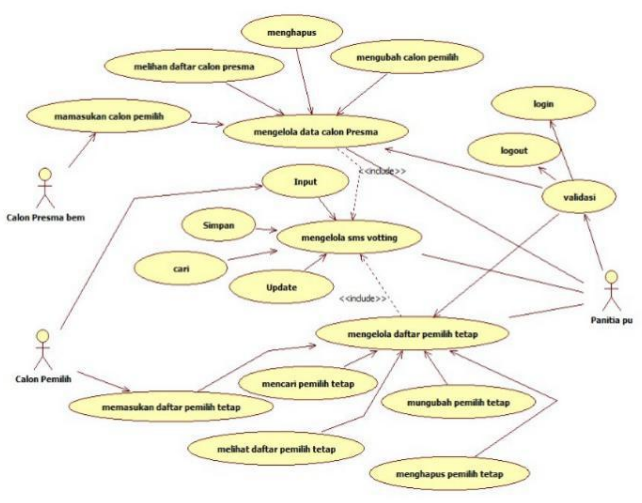

Gambar 3. UseCase Diagram Perancangan Sistem InformasiPemilihan Presma

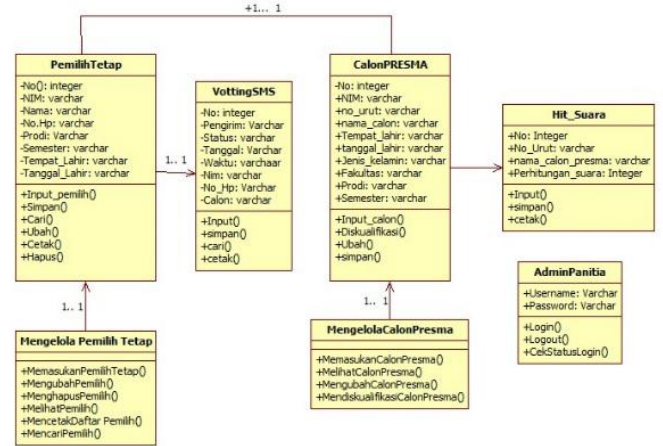


Hal : $102-111$

\begin{tabular}{|l|l|l|l|}
\hline \multicolumn{1}{|c|}{ Field } & \multicolumn{1}{c|}{ Type } & \multicolumn{1}{c|}{ Size } & Keterangan \\
\hline No & Integer & 4 & \\
\hline Nim & Varchar & 15 & Primary key \\
\hline Nama & Varchar & 40 & \\
\hline No_Hp & Varchar & 15 & \\
\hline Prodi & Varchar & 30 & \\
\hline Semester & Varchar & 5 & \\
\hline Tempat_Lahir & Varchar & 30 & \\
\hline Tanggal_Lahir & Varchar & 10 & \\
\hline
\end{tabular}

Tabel 1. Rancangan Tabel Pemilih

TABel 1. RANCANGAN TABel PEMILIH digunakan untuk menyimpan data pada Pemilih tetap.

\begin{tabular}{|l|l|l|l|}
\hline \multicolumn{1}{|c|}{ Field } & \multicolumn{1}{c|}{ Type } & \multicolumn{1}{c|}{ Size } & Keterangan \\
\hline No & Integer & 4 & \\
\hline Status & Varchar & 15 & \\
\hline Pengirim & Varchar & 20 & \\
\hline Tanggal & Varchar & 15 & \\
\hline Waktu & Varchar & 10 & \\
\hline Kode & Varchar & 5 & \\
\hline Nim & Varchar & 30 & Primary key \\
\hline Calon Presma & Varchar & 15 & \\
\hline
\end{tabular}

Tabel II. Rancangan Tabel SMSVotting,

Tabel II digunakan untuk menyimpan data pada tahapan smsvotting dilaksanakan

\begin{tabular}{|l|l|l|l|}
\hline \multicolumn{1}{|c|}{ Field } & \multicolumn{1}{c|}{ Type } & \multicolumn{1}{c|}{ Size } & Keterangan \\
\hline No & Integer & 4 & \\
\hline Nim & Varchar & 15 & \\
\hline No_Urut & Varchar & 3 & Primary Key \\
\hline Nama_calon & Varchar & 40 & \\
\hline Tempat_Lahir & Varchar & 40 & \\
\hline Tanggal_Lahir & Varchar & 10 & \\
\hline Jenis_Kelamin & Varchar & 5 & \\
\hline Fakultas & Varchar & 30 & \\
\hline Prodi & Varchar & 30 & \\
\hline Semester & Varchar & 4 & \\
\hline
\end{tabular}

Tabel III digunakan untuk menyimpan data pada Calon Presma.

\begin{tabular}{|l|l|l|l|}
\hline \multicolumn{1}{|c|}{ Field } & \multicolumn{1}{c|}{ Type } & \multicolumn{1}{c|}{ Size } & Keterangan \\
\hline No & Integer & 4 & \\
\hline No.Urut & Varchar & 3 & Primary key \\
\hline Nama_calon & Varchar & 40 & \\
\hline Perhitungan_suara & Varchar & 2000 & \\
\hline
\end{tabular}

Tabel IV digunakan untuk menyimpan data dari Smsvotting yangdilakukan oleh Pemilih Tetap 


\begin{tabular}{|l|l|l|l|}
\hline \multicolumn{1}{|c|}{ Field } & \multicolumn{1}{c|}{ Type } & \multicolumn{1}{c|}{ Size } & \multicolumn{1}{c|}{ Keterangan } \\
\hline Username & Integer & 20 & Primary key \\
\hline Nama_Admin & Varchar & 40 & \\
\hline Password & Varchar & 8 & \\
\hline
\end{tabular}

Tabel V. Rancangan Tabel Admin

Tabel V digunakan untuk menyimpan data pada Admin Panitia Pemungutan Suara.

4) Infrastruktur SMS Gateway

Gambaran dibawah ini cara kerja dari sistem aplikasi pemilihan Presma melalui Sms Gateway. Pemilih mendaftarkan datadiri dan nomor handphone yangdigunakan pada saat pemilihan ke panita pemilihan Presma, kemudian pihak panitia akan mengirimkan sms masal ke daftar pemilih tetap untuk waktu pelaksanaan selanjutnya pemilih dapat langsung membalas sms tersebut dengan mengisi nomor urut dan calon Presma yang akan dipilihnya, setelahnya proses pengiriman sms tersebut otomatis akan di ambil oleh gammu dan dimasukan ke table perhitungan suara

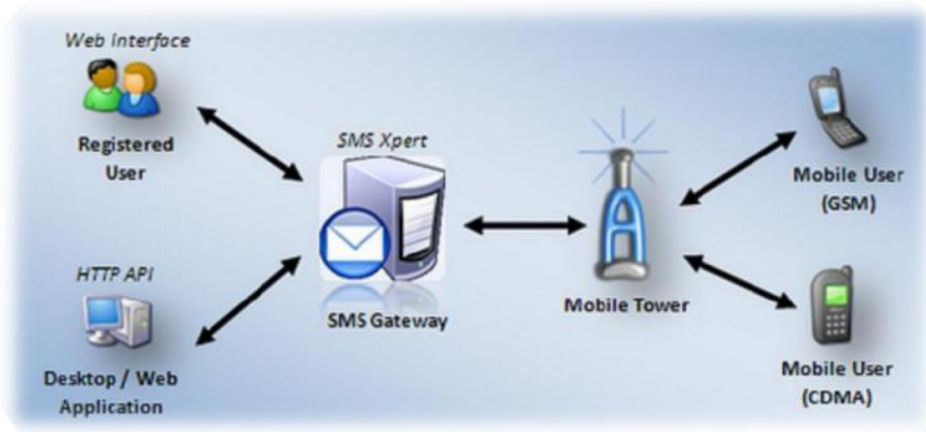

Gambar 5. Ilustrasi cara kerja SMS Gateway
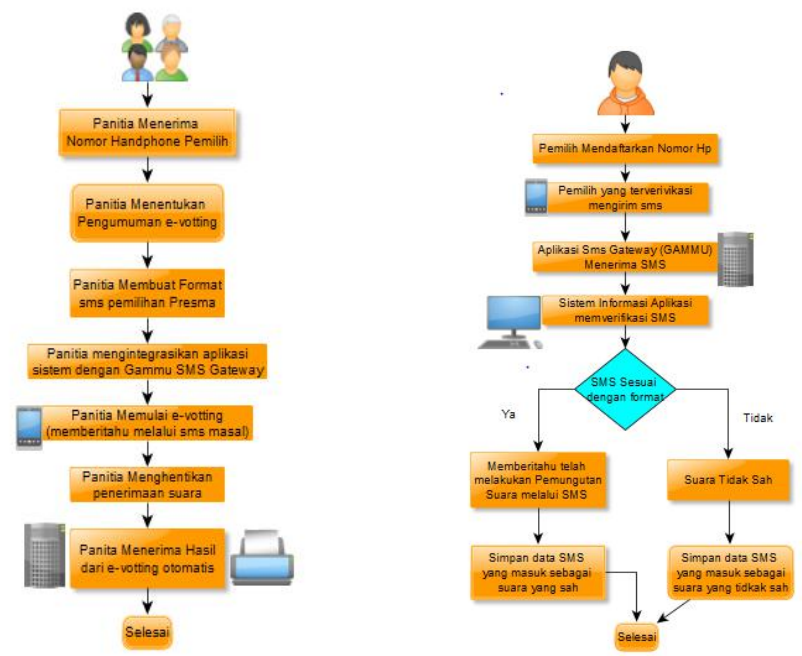

Gambar 6 dan 7 . cara kerja SMS Gateway pada pantia 
Hal : $102-111$

\section{KESIMPULAN}

Berdasarkan hasil penelitian yang telah dilakukan penulis, maka dapat diambil kesimpulan sebagai berikut:

a. Rancang Bangun dan Desain Sistem informasi aplikasi Pemungutan suara melalui evotting akan memberikan informasi-informasi pemilihan presiden mahasiswa dan melakukan pemungutan suara melalui SMS pada pemilih tetap di kampus dan mendapatkan informasi yang cepat, akurat dan efisien.

b. Rancang Bangun dan Desain aplikasi Pemungutan suara melalui e-votting menggunakan SDLC metode Waterfall akan memberikan keluaran berupa grafik mengenai Calon Presma yang di votting oleh pemilih sehingga hasil realcount dapat diketahuhi pada setiap SMS yang masuk dari pemilih tetap dan menghemat pengeluaran untu proses pemilihan Presma Kampus

\section{SARAN}

a. E-voting dengan berbagai aspek peluang, tantangan, kelebihan dan kekurangan dapat menjadikan proses pelaksanaan pesta demokrasi menjadi lebih baik. Penggunaan SMS Gateway dalam melaksanakan pemungutan suara dalam pemilihan Presma adalah hal yang baru yang harus kita terapkan sesuai dengan perkembangan teknologi industry 4.o. di era yang serba digitalisasi kita harus mampu menciptakan pemilihan berbasis e-votting ini menjadi proses pemilihan yang efisien, cepat dan akurat.

b. Pada tahap implementasi, pemrograman diharapkan sesuai dengan analisis dan desain pada penelitian ini agar dapat sesuai dengan hasil dari Analisa dan desain

c. Masih dimungkinkan dalam membangun aplikasi ini menggunakan metode selain RUP dan SDLC Metode waterfall. Dan aplikasi gammu sebagai media SMS Gateway.

VII. Daftar Pustaka

[1]Muslih Taufiq M, Purnama Eka B. 2013. Pengembangan Aplikasi SMS Gateway Untuk Informasi Pendaftaran Peserta Didik Baru Di SMAN 1 Jepara. IJNS, Vol. 2, No. 1, Juli 2013.

[2] Sasmito Wiro G. 2017. Penerapan Metode Waterfall Pada Desain Sistem Informasi Geografis Industri Kabupaten Tegal. Jurnal Informatika, Vol. 2, No. 1, Januari 2017. Politeknik Harapan Bersama.

[3]. Kurniadi Dede. 2014. Rancang Bangun Aplikasi Sistem Pemilihan Kepala Desa yang Terintegrasi dengan SMS Gateway. Jurnal Wawasan Ilmiah Manajemen dan Teknik Informatika, Vol. 6, No. 11, September 2014. Teknik Informatika AMIK Garut.

[4]. Rahardjo Dani, Warkim. Prototipe Sistem Informasi Geografis Fasilitas Kesehatan di Kota Cirebon Berbasis Web. Jurnal Teknik Informatika dan Sistem Informasi, Vol. 1, No. 3, Desember 2015.

[5]. S, Rosa A. dan M. Shalahudin. 2013. Rekayasa Perangkat Lunak Terstruktur dan Berorientasi Objek. Informatika Bandung.

[6]. Siahaan Daniel. Analisa Kebutuhan Dalam Rekayasa Perangkat Lunak. 2012. Andi Yogyakarta.

[7]. Taufik M, Darwiyanto Eko, dkk. Analisis dan Impementasi Perancangan Metode Rational Unified Process pada layanan SDB dan Metode Pengujian Product Metric pada Bank Mandiri Cabang Palu Sam Ratulangi. e-Proceeding of Engineering : Vol.2, No.3 Desember 2015. SSN : 2355-9365. Program Studi S1 Teknik Informatika, School of Computing, Telkom University

[8]. Sriyanto, Ni Putu S. Perancangan Sistem Informasi Pemesanan Berbasis SMS Gateway Untuk Memperbaiki Informasi Persediaan (Studi Kasus : PT 
Hal : $102-111$

Indotirta Jaya Abadi Semarang). Jurnal SIMETRIS, Vol 5 No 2 Nopember 2014 ISSN: 2252-49. Universitas Dipenogoro.

[9]. Priyono Edi, Nurdiana Fereshti D. E-Voting: Urgensi Trasnparansi dan AKuntabilitas. Seminar Nasional Informatika 2010 (semnasIF 2010). ISSN: 1979-2328. UPN "Veteran" Yogyakarta.

[10]. Ristanto Slamet. Aplikasi Pemungutan Suara Elektronik/E-Votting menggunakan Teknologi Short Message Service dan AT Command. Jurnal Teknik Informatika Vol.10 No.1,2017. ISSN 1979 - 1960. Universitas Sangga Buana YPKP Bandung. 